MONOGRAFIA

\title{
Práticas culturais e níveis de competência midiática de jovens brasileiros
}

\author{
Prácticas culturales y niveles de competencia mediática \\ de jóvenes brasileños
}

\section{Cultural practices and media competence levels of young Brazilians}

\author{
Dr. Gabriela Borges \\ Professora Adjunta \\ (Universidade Federal de Juiz de Fora) \\ http://orcid.org/0000-0002-0612-9732 \\ Brasil \\ Dr. Monica Fantin \\ Professora Associada \\ (Universidade Federal de Santa Catarina) \\ http://orcid.org/0000-0001-7627-2115

$$
\text { Brasil }
$$

\author{
Dr. Márcia Barbosa da Silva \\ Professora Adjunta \\ (Universidade Estadual de Ponta Grossa) \\ https://orcid.org/0000-0001-8972-7713 \\ Brasil
}

Dr. Maria Alzira Pimenta

Professora Adjunta

(Universidade de Sorocaba)

https://orcid.org/0000-0002-5775-5856

Brasil

\author{
Dr. Soraya Maria Vieira \\ Professora Associada \\ (Universidade Federal de Juiz de Fora) \\ http://orcid.org/0000-0002-1147-4987 \\ Brasil
}

Data de recepção: 23 de outubro de 2019

Data de revisão: 26 de janeiro de 2019

Data de aceitação: 8 de abril de 2020

Data de publicação: 1 de julho de 2020

Para citar este artigo: Borges, G., Fantin, M., Barbosa da Silva, M., Alzira Pimenta, M. y Vieira, S. M. (2020). Práticas culturais e níveis de competência midiática de jovens brasileiros, Icono 14, 18 (2), 320-352. doi: 10.7195/ri14.v18i2.1460 
MONOGRAFIA

\section{Resumo}

Este artigo apresenta os resultados da pesquisa "Competências midiáticas em cenários brasileiros e euroamericanos" realizada com jovens de 14 a 16 anos de escolas públicas e privadas de seis cidades brasileiras. Foi desenvolvida pelas universidades integrantes da Red Interuniversitaria Euroamericana de Investigación en Competencias Mediáticas para la Ciudadanía (ALFAMED) no Brasil. De caráter quali-quantitativo, avaliou os níveis de cada uma das seis dimensões da competência midiática (Ferrés e Piscitelli, 2015) de 499 estudantes, tendo em conta suas práticas culturais. Os resultados indicam que os jovens aprendem informalmente a lidar com as mídias, possuem nivel avançado no manuseio da tecnologia e nas dimensões linguagem, estética e ideologia e valores. Porém, nas dimensões processos de interação e de produção e difusão, que estão relacionados com o consumo e a participação midiática, encontram-se no nível básico/intermediário, indicando a necessidade de ações formativas para promover a aprendizagem e o desenvolvimento do espírito crítico.

Palavras chave: Competência Midiática; Literacia midiática; Mídia-educação; Cidadania; Participação cívica; Consumo Midiático

\section{Resumen}

Este artículo presenta los resultados de la investigación "Competencias mediáticas en escenarios brasileños y euroamericanos" realizada con jóvenes de 14 a 16 años de escuelas públicas y privadas en seis ciudades brasileñas. Fue desarrollada por las universidades miembros de la Red Interuniversitaria Euroamericana de Investigación en Competencias Mediáticas para la Ciudadanía (ALFAMED) en Brasil. La investigación cualitativa cuantitativa evaluó los niveles de cada una de las seis dimensiones de la competencia mediática (Ferrés y Piscitelli, 2015) de 499 estudiantes, teniendo en cuenta sus prácticas culturales. Los resultados indican que los jóvenes aprenden informalmente cómo tratar con los medios, tienen un nivel avanzado en el manejo de la tecnología y en las dimensiones lenguaje, estética e ideología y valores. Sin embargo, en las dimensiones procesos de interacción y de producción y difusión, que están relacionados con el consumo y la participación en los medios, se encuentran en el nivel básico/intermediario, lo que indica la necesidad de acciones formativas para promover el aprendizaje y el desarrollo del pensamiento crítico. 
MONOGRAFIA

Palabras clave: Competencia mediática; Alfabetización mediática; Educación mediática; Ciudadania; Participación ciudadana; Consumo de medios

\section{Abstract}

This article presents the results of the research project "Media skills in Brazilian and Euro-American settings" conducted with 14 to 16 years old from public and private schools in six Brazilian cities. It was developed by the member universities of the Euro-American inter-university research network on media literacy for citizenship (ALFAMED) in Brazil. From a quantitative and qualitative perspective, it assessed the levels of each of the six dimensions of media competence (Ferrés and Piscitelli, 2015) of 499 students, taking into account their cultural practices. The results indicate that young people learn informally how to deal with media, have advanced level in the handling of technology and in language, aesthetics and ideology and values dimensions. However, in the dimensions of processes of interaction and of production and diffusion, which are related to consumption and media participation, they are at the basic/intermediate level, indicating the need for formative actions to promote learning and the development of critical thinking.

Key Words: Media competence; Media literacy; Media education; Citizenship; Civic participation; Media consumption

\section{Introdução}

A diversidade de práticas midiáticas e culturais que os jovens constroem em suas relações com a cultura digital no contemporâneo tem desafiado a pesquisa e a formação. Afinal, numa era em que a mídia e seus dispositivos tecnológicos têm protagonizado cada vez mais as relações entre as pessoas, diversos desafios se colocam aos que atuam no campo da educação e da comunicação, e um deles diz respeito a saber o que os jovens fazem com as mídias e suas tecnologias. 0 que assistem, produzem e compartilham? Como se relacionam e se apropriam das tecnologias digitais? Que competências demonstram ter? Qual o papel da reflexão nessas práticas? 
MONOGRAFIA

Na cultura digital, Buckingham (2005) afirma que a media literacy é o conhecimento e as habilidades que os estudantes adquirem no processo ensino-aprendizagem sobre as mídias, que necessariamente envolve 'leitura' e 'escrita' de mídias no sentido da reflexão, compreensão crítica e participação ativa (pp.4). Na perspectiva das novas literacias, as complexas interfaces entre lingüística, antropologia e epistemologia são fundamentais para entender as relações entre as práticas sociais e suas negociações de sentidos no contexto da convergência das mídias, tecnologias e linguagens. De tal relação, surge a ideia de information literacy, também ligada ao conceito de media e digital literacy (Rivoltella, 2008, 2010). Esses múltiplos letramentos dizem respeito ao sentido de cidadania, participação e democracia, pois requer conhecer as formas de uso e funcionamento da Internet e seus códigos, de saber acessar, selecionar e certificar informações produzidas, consumidas, veiculadas na Internet e suas redes, considerando a confiabilidade dos websites e a competência para uso, criação/produção e compartilhamento de conteúdos digitais de forma responsável.

Tal processo implica uma reconceitualização de tecnologias para além da visão instrumental dos meios de comunicação visual, eletrônico e digital, a idéia de multiliteracias redefine a articulação dos conceitos e dos campos de forma crítica, expandindo-se em diversas formas de expressão. "0s conhecimentos, as habilidades e as competências necessárias para a plena participação na sociedade contemporânea, e todas essas habilidades são vistas como fundamentalmente vinculadas às práticas intelectuais e sociais conhecidas como alfabetização" (Hobbs, 2006, p. 20).

Tais conceitos e suas interpretações sugerem que as mudanças no processo de ensino-aprendizagem implicam diálogo, negociação, polifonia, abertura, flexibilidade, crítica e colaboração numa perspectiva transformadora que necessita o desenvolvimento e a construção de certas competências.

Ao situar o conceito de competência, Rivoltella (2005) enfatiza a importância das multicompetências na cultura digital, e destaca três linhas de atuação: i) explicitar e problematizar as competências tácitas para se ter a consciência de determinados processos; ii) desenvolver a capacidade de reflexão; e iii) possuir a competência das competências, que são múltiplas e variadas e favorecem o desen- 
MONOGRAFIA

volvimento de metacompetências, entendidas como a capacidade de organizar as diferentes dimensões (pp. 4).

No quadro mais amplo das oito competências-chaves propostas em diversos documentos da União Europeia $(2006,2018)$ e European Commission (2019): 1. Competências de literacia (língua materna); 2. Competências linguísticas; 3. Competências em matemática e no domínio das ciências, da tecnologia e da engenharia; 4. Competências digitais; 5 . Competências pessoais, sociais e capacidade de aprender a aprender; 6 . Competências de cidadania; 7. Competências de empreendedorismo e 8. Competências de sensibilidade e expressão culturais - é possível discutir a especificidade das competências midiáticas de crianças e jovens, que se relacionam e/ou incluem as competências digitais. Inclusive, o documento DigComp: the European Digital Competence Framework (European Commission, 2018) define cinco áreas de atuação: literacia de dados e da informação, comunicação e colaboração, criação de conteúdo digital, segurança e resolução de problemas.

Garcia-Ruíz e Pérez e Gomez (2014, p. 16) esclarecem o percurso histórico de diversos organismos internacionais em diferentes países (OCDE, UNESCO) em que a educação midiática nas escolas é vista como possibilidade de melhorar o acesso aos meios e tecnologias.

La alfabetización y educación mediática se ha convertido, por tanto, en una necesidad de primer orden, que ha llevado a promover una educación crítica, activa y plural en torno a los medios (Aguaded, 2012; Gutiérrez \& Tyner, 2012), cuyo objetivo es aumentar la concienciación de los ciudadanos sobre las múltiples formas de mensajes difundidos por los medios con que se pueden encon-trar en su vida diaria (European Commission, 2009) (Garcia-Ruíz, Pérez e Gomez, 2014, p.16).

Na definição da Comissão Europeia a competência midiática se refere à capacidade de acessar aos meios de comunicação (entre eles televisão, cinema, rádio, meios impressos, internet e todas as outras tecnologias de comunicação digital), compreender e avaliar criticamente os diferentes aspectos e conteúdos dos mesmos e à criação das comunicações em uma variedade de contextos, esclarece Aguaded (2012, p.8). E de 
MONOGRAFIA

acordo com tal entendimento, Ferrés e Piscitelli (2015) enfatizam a importância de conceber a educação midiática de maneira ativa, participativa e lúdica.

Nessa perspectiva, o conceito de competência midiática se refere a "uma combinação de conhecimentos, habilidades e atitudes que se consideram necessários para um determinado contexto" (Ferrés \& Piscitelli, 2015, p. 3).

Embora entenda que o fenômeno da comunicação e de todas as práticas e relações humanas sejam complexos e estejam sempre em constante relação, Ferrés e Piscitelli (2015), atualizando estudo de Ferrés (2007, p. 103), elaboram seis dimensões para melhor compreender a construção da competência midiática: linguagem (sentido plural, multimodal e multimedial); tecnologia (ferramentas/funções); estética (sensibilidade/ criatividade); processos de produção e difusão (como, porque, para que e para quem produzir); ideologia e valores (reconhecimento de conteúdos veiculados às mensagens e estereótipos presentes); processos de interação (interação com as mensagens recebidas) e estética (análise formal e temática com sentido estético e sua relação com outras manifestações). Estas dimensões devem ser entendidas de forma inter-relacionada e a partir do âmbito da análise (que se refere ao modo como as pessoas recebem e interagem com as mensagens) e da expressão (relativo ao modo como as pessoas produzem as mensagens a partir de seus próprios entendimentos de mundo).

É a partir deste enquadramento desenvolvido pela pesquisa que destacamos, a seguir, alguns aspectos relativos aos consumos e às práticas culturais relacionados às dimensões da competência midiática de jovens estudantes brasileiros.

\section{Material e Métodos}

A pesquisa "Competências midiáticas em cenários brasileiros e euroamericanos"1 foi desenvolvida entre os anos de 2014 a 2019 pelos integrantes da rede ALFAMED - Brasil ${ }^{2}$. Realizada em conjunto com a Universidade de Huelva na Espanha e articulada com outras pesquisas dos países da rede, a pesquisa procurou levantar as demandas relacionadas às competências no âmbito nacional para posterior comparação com os resultados obtidos pelos outros países da rede. 
MONOGRAFIA

0 objetivo desta pesquisa foi investigar os níveis de competência midiática de diferentes segmentos: crianças de 9 a 12 anos, jovens de 14 a 16 anos, jovens universitários, professores universitários e profissionais da comunicação. Sob a coordenação da Universidade Federal de Juiz de Fora, cada universidade se envolveu na pesquisa a partir de subprojetos que incluíam pelo menos dois segmentos de acordo com as características dos grupos de pesquisas envolvidos. Neste artigo será enfocado o segmento de jovens de 14 a 16 anos, do qual seis universidades participaram da coleta de dados.

A metodologia empregada partiu de uma abordagem quali-quantitativa (Creswell, 2010). Nas ciências sociais, as abordagens de pesquisa têm sido eminentemente qualitativas, visando a compreensão dos processos de significação e colocando em relevo a perspectiva dos participantes (Schneider, Fujii \& Corazza, 2017). No entanto, entendemos que dados numéricos e quantificáveis podem contribuir para a compreensão dos fenômenos sociais. Gatti (2004) salienta que a articulação de dados quantitativos e qualitativos contribuem para o entendimento das situações de pesquisa e alerta para a importância do "esforço de reflexão do pesquisador para dar sentido ao material levantado e analisado" (pp.13).

Esta pesquisa é de natureza exploratório-descritiva com dados coletados por meio de questionários (Hernández Sampieri; Fernández-Collado; Baptista-Lucio, 2013; Gil, 2008) com o objetivo de compreender os níveis de competência midiática e analisar como os públicos estudados se comportam no contexto brasileiro, uma abordagem ainda pouco estudada no país.

A pesquisa foi constituída de diferentes etapas articuladas e complementares. A etapa inicial teve como objetivo a formação das equipes em cada uma das universidades e de grupos de estudos liderados pelos coordenadores locais. 0s estudos englobaram os temas: Literacia midiática, competências midiáticas e mídia-educação numa perspectiva brasileira e comparativa com a Espanha e América Latina. A segunda etapa abrangeu a elaboração dos instrumentos de coleta de dados (questionários) em língua portuguesa e espanhola para os diferentes segmentos da pesquisa. A terceira etapa consistiu na aplicação dos questionários no Brasil e nos demais países participantes da pesquisa e a validação dos dados, feita posteriormente pela Universidade de Huelva. 
MONOGRAFIA

Para a aplicação dos questionários foram contatadas as escolas públicas e privadas de cada região e realizados os procedimentos relativos ao consentimento livre e esclarecido dos alunos e seus responsáveis. 0s alunos tiveram acesso ao questionário por meio de aplicativo online elaborado pela equipe espanhola. As escolas, em sua maioria, disponibilizaram os laboratórios de informática para a realização da pesquisa.

Na etapa seguinte os dados foram tratados estatisticamente e feita uma avaliação dos resultados. Num primeiro momento foram analisados os dados referentes à cada dimensão, e na sequência foram organizados os dados referentes aos níveis de competência distribuídos por meio de valores correspondentes às seguintes categorias: básico, básico/intermediário e avançado. Também cruzamos os dados de acordo com o sexo, idade, tipo de escola e formação com o fim de verificar as variações ocorridas a partir dessas categorias. 0 s resultados serão apresentados a seguir.

0 questionário foi composto por 27 perguntas abertas e de múltipla escolha, com o objetivo de traçar o perfil dos estudantes e avaliar o desenvolvimento da competência midiática. Após a aplicação do questionário nas escolas, de forma presencial e com o acompanhamento da equipe do projeto, as respostas obtidas foram organizadas em um arquivo do $\mathrm{Excel}^{3} \mathrm{e}$, posteriormente, realizamos a sistematização dos dados no software R.

0 questionário foi dividido em duas etapas, inicialmente 0 aluno respondia nove perguntas relacionadas ao seu perfil como, por exemplo, sexo, idade, cidade, escola, etc. Num segundo momento, as questões foram direcionadas para as seis dimensões da competência midiática sugeridas por Ferrés e Piscitelli (2015): linguagem, tecnologia, processos de interação, processos de produção e difusão, ideologia e valores e estética, que abarcou três perguntas, totalizando 18 questões.

A pesquisa foi realizada com 499 alunos, entre 14 e 16 anos, do ensino médio de seis ${ }^{4}$ cidades brasileiras. São elas Brasília (DF), Florianópolis (SC), Juiz de Fora (MG), Ponta Grossa (PR), São Roque (SP) e Sorocaba (SP). 
MONOGRAFIA

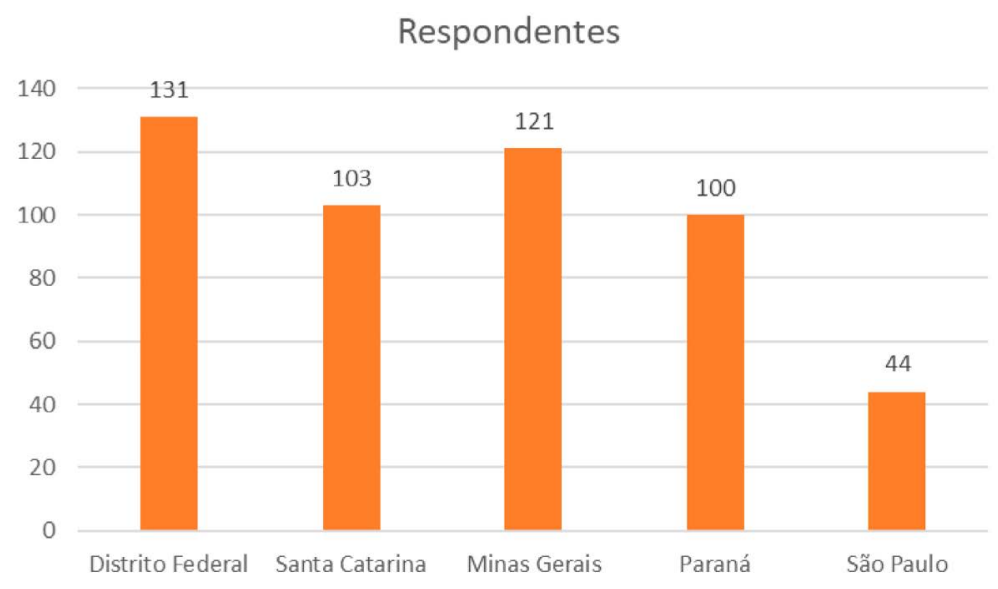

Figura 1: Respondentes

Fonte: Elaborado pelas autoras (2019).

Para a organização dos dados ${ }^{5}$, com o intuito de obter informações consistentes, foi feita uma padronização de variáveis pelo nome mais frequente, esta ação foi necessária pois os respondentes inseriam diferentes formas para o mesmo nome de escola ou cidade, como, por exemplo MG, MINAS GERAIS e Minas Gerais, e assim por diante. Após depuração da base de dados foi utilizado o software estatístico $R$ (https://www.r-project.org/) de livre distribuição e código aberto para a geração dos primeiros resultados. Na sequência foi utilizado o software Crosstab e teste quiquadrado ${ }^{6}$ para um refinamento dos dados que possibilitou a leitura dos níveis de competência e o cruzamento desses níveis conforme as variáveis de perfil dos respondentes

\section{Resultados}

0 perfil dos participantes da pesquisa é composto por jovens entre 14 e 16 anos, sendo que $53,31 \%$ são do gênero feminino e $46,69 \%$ masculino. Segundo os dados da pesquisa ${ }^{7}, 67,74 \%$ dos alunos frequentam a escola pública, $25,5 \%$ é da rede privada e $6,21 \%$ é da rede privada com apoio público. 0s perfis socioculturais de cada contexto participante da pesquisa variam muito, envolvendo uma diversidade quanto às origens de classe, condições sociais, etnias, procedências geográficas e capital cultural, o que dificulta certas generalizações. 
329 | Gabriela Borges, Monica Fantin, Márcia Barbosa da Silva, Maria Alzira Pimenta, y Soraya Maria Vieira MONOGRAFIA

\section{Amostra da pesquisa}

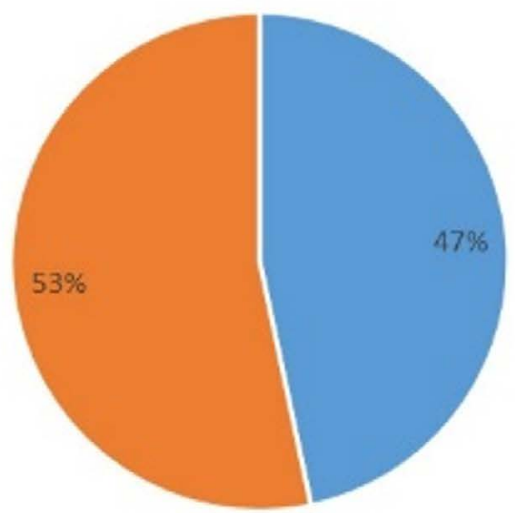

- Masculino = Feminino

Figura 2: Amostra da pesquisa

Fonte: Elaborado pelas autoras (2019).

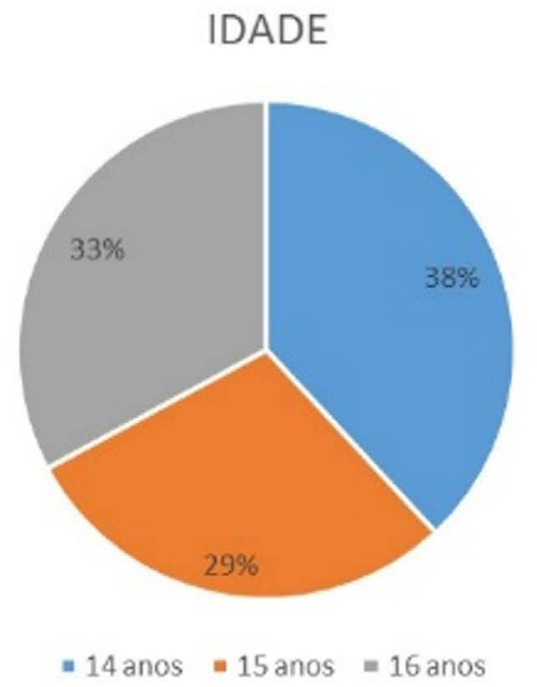

Figura 3: Idade dos respondentes

Fonte: Elaborado pelas autoras (2019). 
MONOGRAFIA

\section{Tipos de escolas}

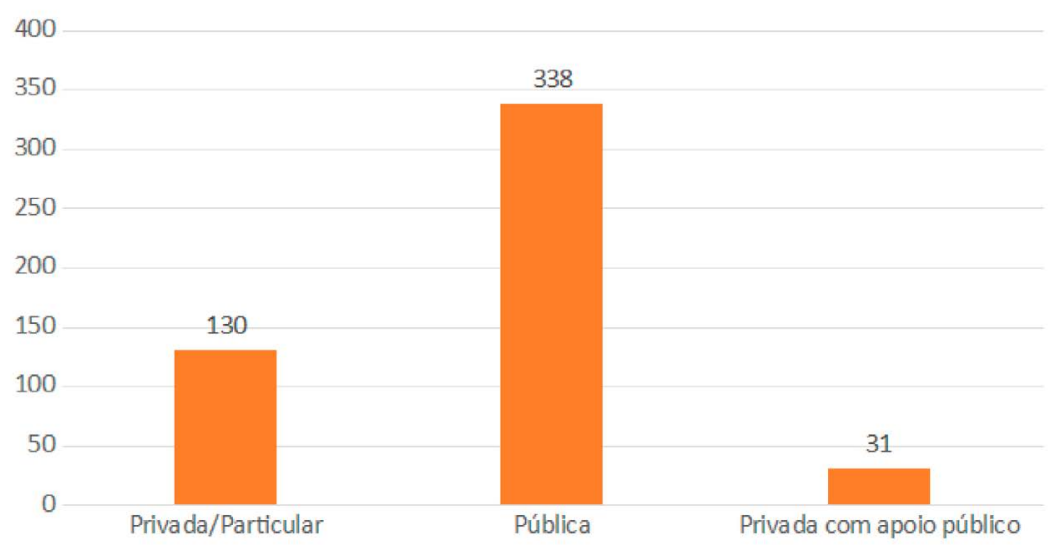

Figura 4: Tipos de escolas

Fonte: Elaborado pelas autoras (2019).

Em relação aos equipamentos e serviços que tinham acesso e/ou à disposição, 96,99\% dos alunos possuem televisão, 93,59\% possuem smartphone e 80,76\% possuem computador/notebook. Os itens filmadora e máquina fotográfica digital foram respectivamente $46,69 \%$ e $61,32 \%$, e provavelmente estão contemplados nos demais aparelhos que possuem tal função. $0 \mathrm{mp} 3^{8} / \mathrm{mp} 4^{9}$ foi o menos assinalado, com apenas $31,46 \%$, conforme pode ser observado no gráfico abaixo.

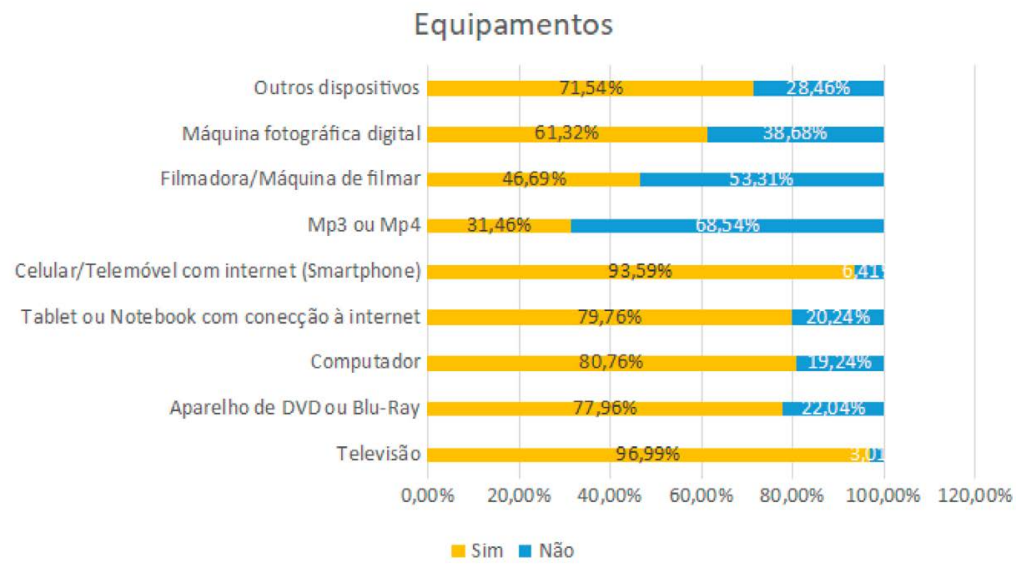

Figura 5: Equipamentos e/ou dispositivos que estudantes têm à disposição e/ou acessam. Fonte: Elaborado pelas autoras (2019). 
MONOGRAFIA

A partir deste contexto, analisamos a seguir os resultados encontrados na análise de cada uma das seis dimensões da competência midiática analisadas.

\subsection{Tecnologia}

A dimensão tecnologia se refere à capacidade de manejo das inovações tecnológicas que possibilitam uma comunicação multimodal e multimedial (Ferrés \& Piscitelli, 2015, p. 10). As perguntas procuram entender as formas de uso e o conhecimento dos respondentes sobre buscas na internet, uso de softwares e aplicativos. Sobre o critério de escolha do navegador, $65,13 \%$ dos alunos responderam que a rapidez é um fator determinante. 0 segundo critério citado pelos respondentes foram os recursos de navegabilidade $(15,83 \%)$. Em relação ao modo como procuram informação, foi perguntado aos estudantes quais palavras eles escreveriam em um site de busca (Google, Bing, etc.) para pesquisar as etapas literárias de Gabriel García Márquez. De acordo com as respostas, 37,88\% dos jovens marcaram a opção "Etapas literárias Gabriel García Márquez" e 34,27\% optaram por segmentar a busca usando as aspas ("“') entre o termo de busca "As etapas literárias de Gabriel García Márquez". Quando questionados se usam softwares e/ou aplicativos para editar imagens $54,91 \%$ responderam "sim". Dessa forma, podemos concluir que os respondentes têm compreensão crítica do ambiente digital e conseguem editar imagens através de programas.

Em relação aos níveis de competência midiática, a dimensão tecnologia apresentou a maior percentagem de respondentes no nível avançado.

Tecnologia

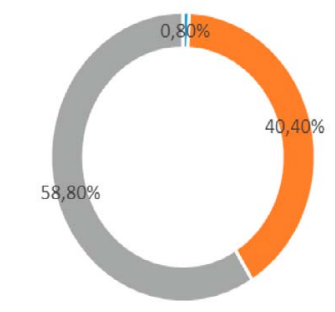

- Básico = Básico/Intermediário | Avançado

Figura 6: Niveis de competência midiática da dimensão tecnologia Fonte: Elaborado pelas autoras (2019). 
MONOGRAFIA

Em relação à categoria sexo, $60,70 \%$ do sexo feminino e $56,60 \%$ do sexo masculino obtiveram um nível avançado, mostrando um equilíbrio nesta dimensão no que se refere à questão de gênero. Em relação à idade foi possível perceber um crescimento gradativo do nível avançado conforme a idade: 14 anos (52,60\%), 15 anos $(58,90 \%)$ e 16 anos $(65,70 \%)$, indicando que a experiência acumulada auxilia na apreensão desta dimensão.

Já em relação ao tipo de escola frequentada a maior porcentagem para o nível avançado foi registrada na escola privada $(66,4 \%)$, seguida da escola pública $(56,60 \%)$ e da privada com apoio público (50\%), evidenciando um equilíbrio entre os níveis avançado e básico/intermediário. Em relação à formação, as respostas apontam um equilíbrio entre aqueles que estão no nível avançado e aprenderam a usar a tecnologia por meio de workshops $(71,4 \%)$ e aqueles que afirmam ser autodidatas $(70,4 \%)$. Por outro lado, $64,9 \%$ daqueles que estão no nível básico/ intermediário afirmam que aprenderam com os professores.

\subsection{Linguagem}

A dimensão linguagem abrange a capacidade de interpretar e avaliar diversos códigos de representação, bem como ser capaz de modificar produtos existentes conferindo-lhes um novo sentido e valor (Ferrés \& Piscitelli, 2015, p. 9). As perguntas direcionadas a esta dimensão foram relacionadas às cenas de filmes e à produção de vídeos. Após a exibição de uma sequência ${ }^{10}$ do longa metragem 0 Fabuloso Destino de Amélie Poulain (Le fabuleux destin d'Amélie Poulain, 2001, França) os estudantes responderam a seguinte questão: Qual destas opções sobre 0 uso da linguagem audiovisual melhor representa o significado do fragmento deste filme. 51,90\% sinalizaram a opção "A câmera próxima de Amélie destaca 0 seu estado emocional", 24,65\% afirmaram que $A$ música serve para ambientar a época em que se passa a sequência e $23,45 \%$ responderam que "As cores refletem a tristeza da personagem principal do filme". Nesse sentido, podemos ressaltar que a maioria dos estudantes identificou as diferentes linguagens envolvidas na comunicação midiática. 

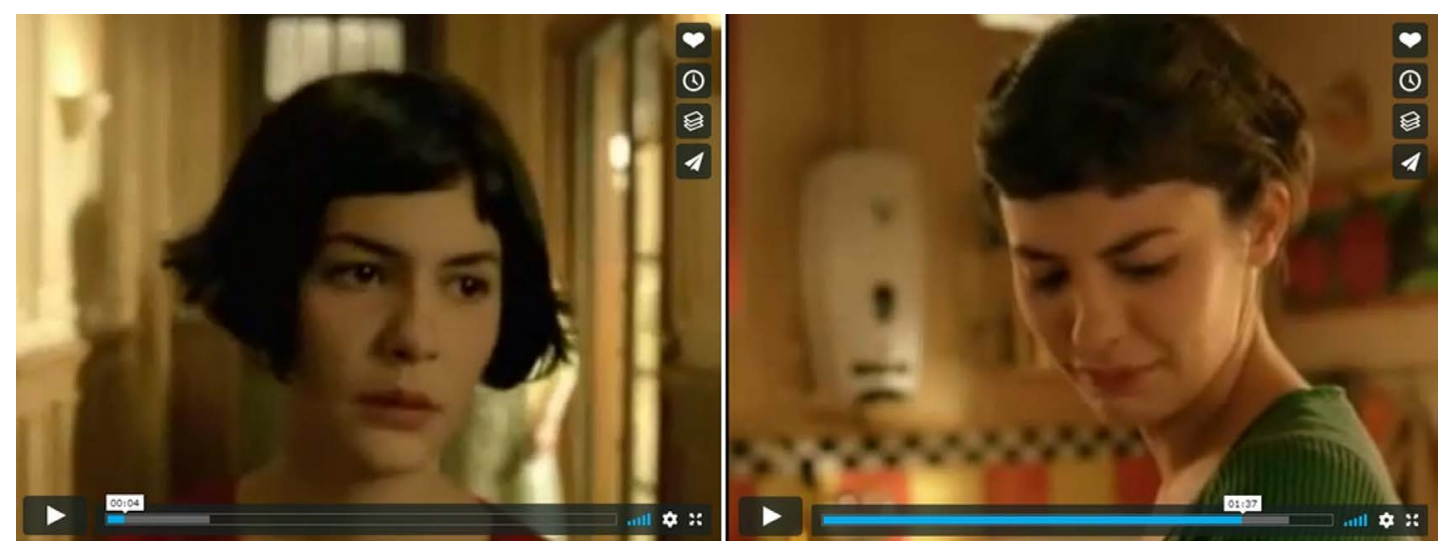

Figura 7: Cena do filme Amélie Poulain exibida para os alunos.

Fonte: Captura de Tela (2019).

A segunda pergunta da dimensão linguagem estava relacionada a uma sequência do filme Harry Potter e a Ordem da Fênix (Harry Potter and the Order of the Phoenix, 2007, Estados Unidos). 0s alunos tiveram que responder, a partir de uma cena do longa-metragem, que elementos contribuíram para tornar a sequência exibida mais emocionante. 50,50\% dos estudantes afirmaram que foram "As imagens dos amigos de Harry Potter", 28,26\% disseram que foi " 0 cenário e a iluminação" e $21,24 \%$ enfatizaram "0 enquadramento do Harry no chão". Podemos concluir que a maioria dos alunos foi capaz de identificar o significado das diferentes linguagens envolvidas na trama.
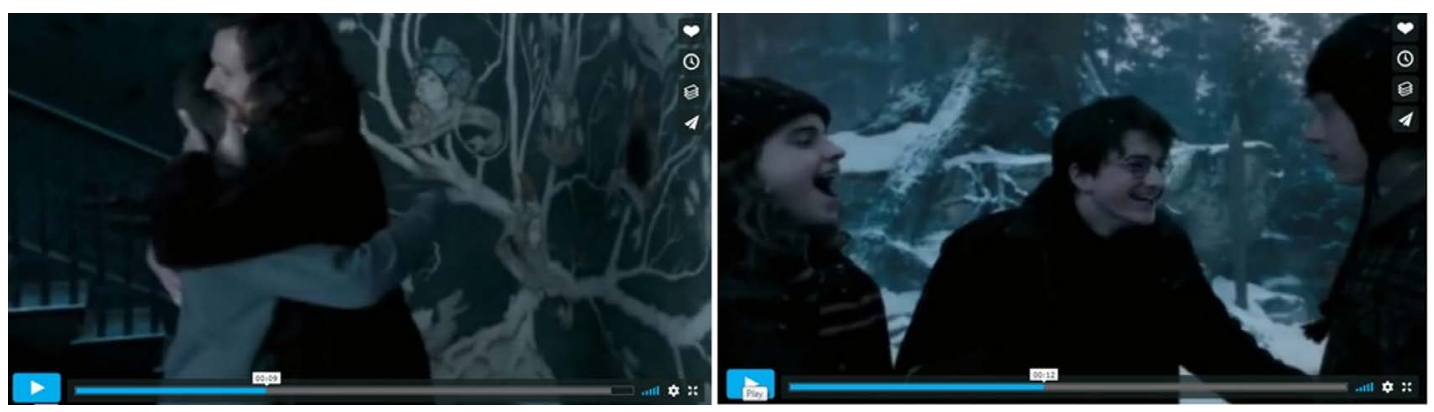

Figura 8: Cena exibida para os alunos.

Captura de Tela (2019). 
A última pergunta referente à dimensão tecnologia estava relacionada à produção de vídeos. Quando questionados se gravavam vídeos, 53,51\% responderam "de vez em quando". Mostrando que estavam familiarizados com o processo de gravação desse tipo de conteúdo.

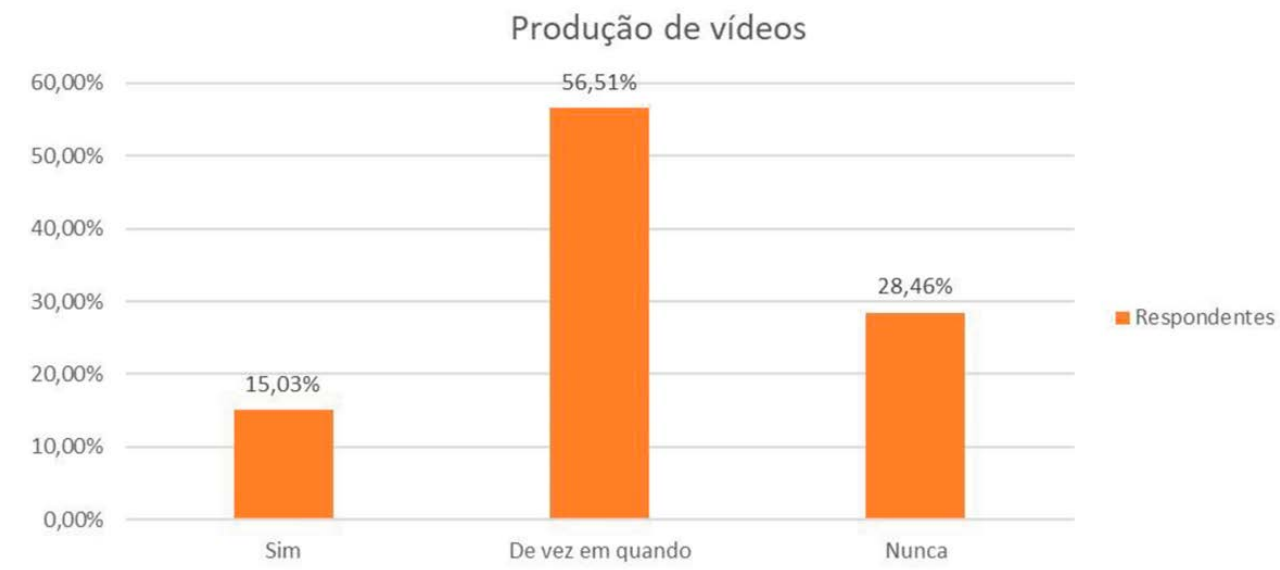

Figura 9: Produção de vídeos por parte dos respondentes

Fonte: Elaborado pelas autoras (2019).

Na análise do nível de competência midiática da dimensão linguagem, constatamos que houve um equilíbrio entre os jovens no nivel avançado (51\%) e nivel básico/intermediário (47\%), sendo este reforçado na variável sexo, com 51,3\% na categoria feminino e $51,50 \%$ na categoria masculino.

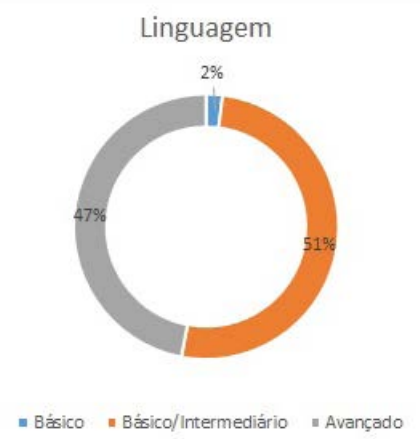

Figura 10: Niveis de competência midiática da dimensão linguagem Fonte: Elaborado pelas autoras (2019). 
Este equilíbrio também se mostrou em relação à faixa etária se mantendo nos 14 anos (50,5\%) e 15 anos (50\%) e mostrando um ligeiro aumento nos 16 anos $(53,6 \%)$. Em relação ao tipo de escola, houve uma prevalência da escola privada $(55 \%)$ sendo seguida pela escola pública $(52,2 \%)$. Na escola privada com apoio público 71,95 dos jovens encontram-se no nível básico/intermediário.

Os dados da categoria formação mostram uma prevalência do nível básico/intermediário, apresentando diferenças de mais de 5 pontos percentuais em relação ao nível avançado. No nível básico/intermediário destaca-se que 71,4\% dos jovens afirmaram ter adquirido conhecimento por meio de workshops, 58,6\% por meio dos professores, $54,3 \%$ por meio de amigos e colegas e 51,3\% afirmam que não adquiriram formação. Em relação ao nível avançado, 51,1\% indicaram os familiares. Portanto, os resultados mostram que a formação recebida, tanto por meio de workshops quanto de professores, não foi suficiente para alcançar o nível avançado neste quesito da dimensão linguagem.

\subsection{Processos de interação}

A dimensão dos processos de interação se refere à capacidade de apreciar mensagens provenientes de outras culturas, bem como trabalhar de forma colaborativa nas redes sociais digitais (Ferrés \& Piscitelli, 2015, p. 10). Nesse contexto, foi exibido para os estudantes um comercial da marca Coca-Cola.

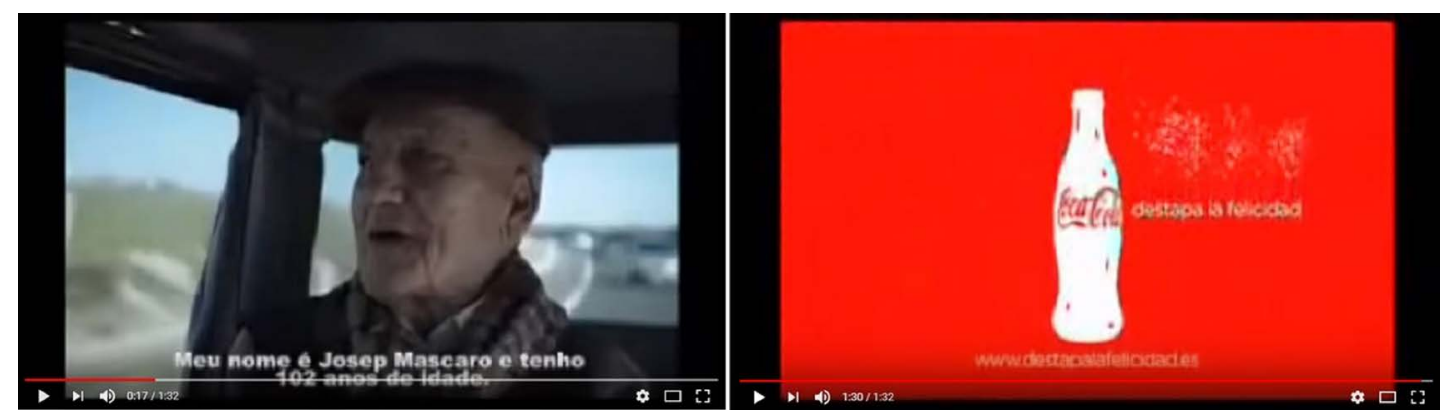

Figura 11: Comercial da Coca-Cola exibido para os alunos.

Fonte: Captura de Tela (2019). 
MONOGRAFIA

Posteriormente, os respondentes tiveram que assinalar a principal intenção do vídeo. A maioria, 41,08\%, dos alunos marcou a opção “Pessoas de qualquer idade podem viver juntas e felizes".

\section{Intenção do vídeo}

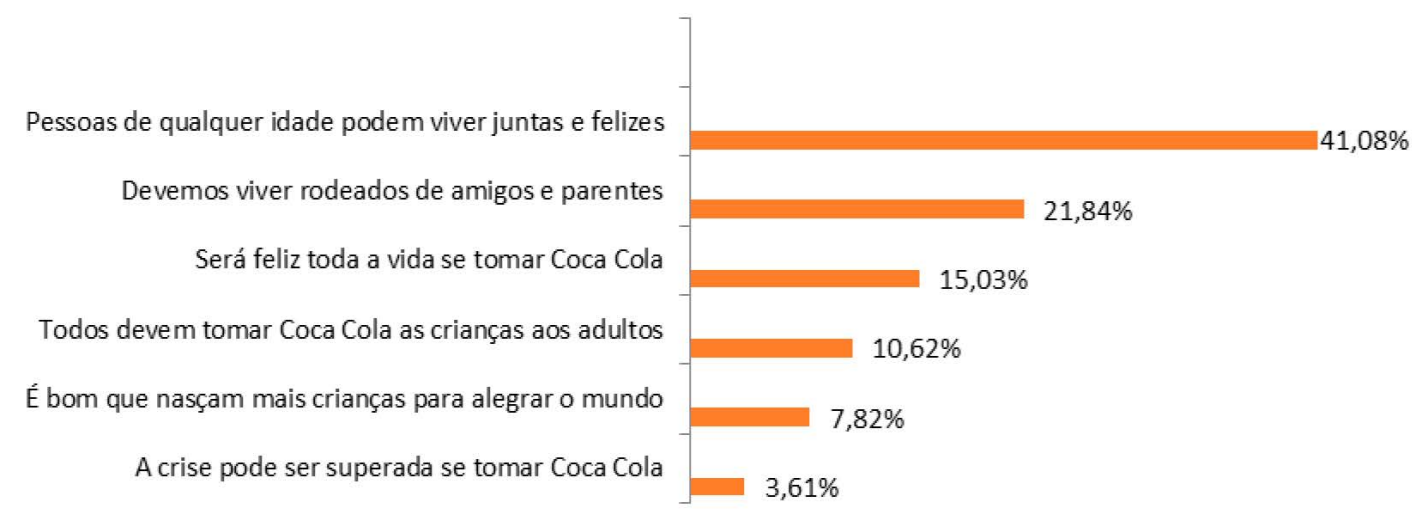

Figura 12: Resposta dos alunos

Fonte: Elaborado pelas autoras (2019).

Com base nas opções marcadas pelos estudantes podemos concluir que a maior parte dos respondentes não compreendeu a real intenção da imagem.

Em relação ao mesmo comercial, foi perguntado aos alunos qual era a influência exercida pelas cenas que tinham acabado de assistir. A partir da questão "Se sim ou talvez, por que influencia?" 32,26\% afirmaram que a influência se deu "porque expõe as emoções que geram o desejo de ter o produto" e 25,65\% assinalaram a opção "porque o consumo se associa aos momentos afetivos". 0s dados mostram que a maioria dos respondentes identificou o valor de uso do produto e o valor emocional associado a ele.

A última questão da dimensão processos de interação foi direcionada à divulgação de postagens inadequadas. Quando questionados se já tinham visto alguma mensagem/post online (sites, redes sociais, etc.) que merecesse ser denunciada $48,90 \%$ dos estudantes afirmaram que já tinham visto e denunciado, 32,26\% nunca tinham visto postagens deste tipo e $18,84 \%$ tinham visto, mas não sabiam como 
MONOGRAFIA

denunciar. Com base nas respostas, podemos ressaltar que os alunos reconhecem as mensagens inadequadas e sabem como agir diante delas.

Em relação ao nível de competência midiática, na dimensão processos de interação, 61\% dos alunos encontram-se no nível básico/intermediário, enquanto $34,4 \%$ estão no nível avançado e 4,6\% no nível básico, conforme gráfico a seguir.

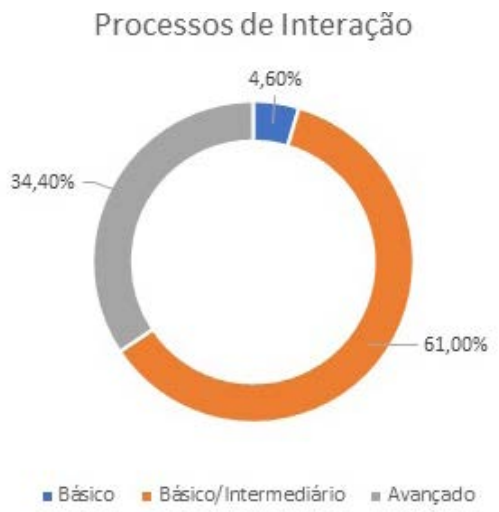

Figura 13: Níveis de competência midiática da dimensão processos de interação Fonte: Elaborado pelas autoras (2019).

Quanto à idade, 68,4\% dos jovens de 14 anos, 56,2\% dos jovens de 15 anos e $56,6 \%$ de 16 anos encontram-se no nível básico/intermediário. Porém, percebe-se que o nível avançado cresce à medida que a idade aumenta, apresentando os seguintes números: $27,9 \%$ (14 anos), 37,7\% (15 anos) e 39,2\% (16 anos), embora todos eles estejam ainda abaixo dos $40 \%$. Em relação ao tipo de escola, houve uma prevalência do nível básico/intermediário com os seguintes números: escola privada $(50,4 \%)$, pública $(63,4 \%)$ e escola privada com incentivo público $(78,1 \%)$. Em relação ao nível avançado, a escola privada $(46,6 \%)$ ainda lidera, com grande diferença em relação às outras: pública $(31,6 \%)$ e escola privada com incentivo público $(15,6 \%)$.

Na categoria formação também houve a prevalência do nível básico/intermediário com todos os quesitos acima de $56 \%$. Podemos destacar, em relação ao nível avançado, uma equiparação entre aqueles que dizem ter adquirido conhecimento com amigos/colegas $(35,8 \%)$, professores $(35,10 \%)$ e autodidatas $(37,8 \%)$. 
MONOGRAFIA

\subsection{Processos de produção e difusão}

A dimensão processos de produção e difusão abrange conhecimentos básicos sobre os sistemas de produção, das técnicas de programação e dos mecanismos de difusão (Ferrés \& Piscitelli, 2015, p. 12). A primeira questão referente a esta dimensão dá continuidade à discussão anterior. Diante de uma postagem inadequada $82,36 \%$ dos respondentes disseram que reportariam ao site responsável, ao invés de conversar com amigos e contar para outras pessoas. Nesse sentido, os estudantes compreendem as medidas adequadas ao se depararem com esse tipo de conteúdo.

A segunda questão solicitava aos alunos que enumerassem as etapas de uma produção audiovisual. 0 enunciado detalhava o seguinte contexto: Imagine que vai participar de um concurso de vídeo em que deve contar uma história sobre alguns personagens. Como organizaria os seguintes passos para realizar uma produção? $49,90 \%$ afirmaram que o primeiro passo seria "Escrever o roteiro" e o segundo passo, para 53,71\% dos estudantes, seria "Combinar, reunir ou definir uma equipe e realizar a pré produção". Posteriormente, 54,91\% dos alunos pontuaram que 0 terceiro passo seria a "Captação audiovisual" e 62,32\% assinalaram que a quarta e última fase seria a "Montagem/Edição". Com base nas porcentagens, podemos observar que a maioria dos respondentes conhece o processo do planejamento/realização de um conteúdo audiovisual, uma vez que a ordem correta foi selecionada mais vezes.

Quando questionados se costumavam compartilhar seus vídeos $61,92 \%$ dos estudantes marcaram a opção "Sim, quando acho conveniente". Já 27,66\% assinalaram "Não, porque não sei" e apenas 10,42\% marcam a opção "Sim". Dessa forma, concluímos que grande parte dos alunos sabe como publicar um vídeo na internet, porém, pondera antes de postar.

A dimensão processos de produção e difusão apresenta $93,60 \%$ dos alunos no nível básico/intermediário, sendo que apenas 4,4\% está no nível avançado e outros 2\% no nível básico. 


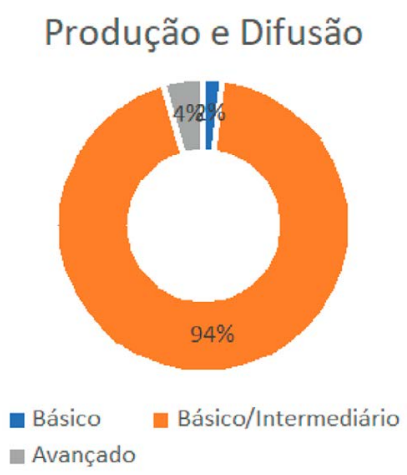

Figura 14: Níveis de competência midiática da dimensão processos de produção e difusão Fonte: Elaborado pelas autoras (2019).

Em relação à variável sexo, os dados mostram um ligeiro aumento no percentual do nível básico/intermediário das meninas $(94,4 \%)$ em comparação com os meninos $(92,8 \%)$, indicando que as meninas são um pouco mais ativas em relação à produção e difusão. Quanto à idade, foram registrados os seguintes valores: 14 anos $(95,3 \%)$, 15 anos $(93,8 \%)$ e 16 anos $(91,6 \%)$, indicando que os mais jovens são mais ativos.

Com relação ao tipo de escola, foram registrados os seguintes percentuais no nível avançado: escola privada $(5,3 \%)$, na escola pública $(4,4 \%)$ e privada com incentivo público $(0 \%)$, sendo que todas elas apresentam pelo menos $93 \%$ dos alunos no nível básico/intermediário.

No que diz respeito à formação adquirida, os dados obtidos para o nível avançado mostram que $14,3 \%$ dos alunos afirmam que aprenderam por meio de workshops, $6,8 \%$ afirmam ser autodidatas e 4,3\% aprenderam com familiares. Ressalta-se ainda que $14,3 \%$ daqueles que se encontram no nível básico afirmam ter aprendido em workshops e a maioria, mais de $70 \%$, em todos os quesitos, encontram-se no nível básico/intermediário.

\subsection{Ideologia e valores}

A dimensão Ideologia e Valores se refere à capacidade de avaliar a flexibilidade frente às informações extraindo conclusões críticas tanto do que se diz quanto do 
que se emite (Ferrés \& Piscitelli, 2015, p. 13). As perguntas que abrangem esta dimensão dialogam com outras questões discutidas nesta análise. A primeira dá continuidade às questões levantadas após a exibição do comercial da Coca Cola e indaga: Acha que esse anúncio pode influenciar as pessoas a consumirem Coca Cola? De acordo com as respostas, conclui-se que os estudantes reconhecem a influência da publicação no consumo do produto, 41,88\% dos alunos responderam "Talvez", 40,48\% assinalaram "Sim" e apenas 17,64\% optaram pela alternativa "Não".

A segunda pergunta retoma a discussão das publicações inapropriadas. Quando questionados sobre a possibilidade de denunciar uma mensagem, 55,91\% dos respondentes pontuaram que seria o teor ofensivo do conteúdo, 36,87\% ressaltaram o vazamento de dados pessoais e $7,21 \%$ reportaram que uma publicação esteticamente feia poderia levá-los a denunciar. Nesse sentido, a denúncia da maioria dos alunos seria motivada por posts agressivos e desrespeitosos. Por fim, a última pergunta da dimensão Ideologia e Valores destaca o compartilhamento de vídeos. A maioria dos respondentes $(56,51 \%)$ afirma que a importância do tema é o que leva ao compartilhamento do conteúdo.

A dimensão ideologia e valores apresenta 59,2\% dos respondentes no nível avançado e 40,8\% no nível básico/intermediário, conforme gráfico a seguir.

\section{Ideologia e Valores}

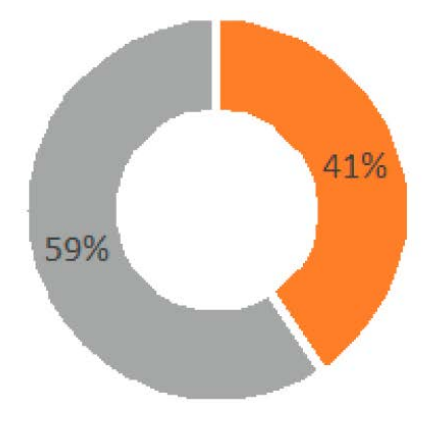

Básico

Básico/Intermediário

Avançado

Figura 15: Níveis de competência midiática da dimensão ideologia e valores Fonte: Elaborado pelas autoras (2019). 
MONOGRAFIA

Quando comparado na categoria sexo, o nível avançado teve uma boa variação entre feminino $(63,7 \%)$ e masculino (54\%). Já em relação à idade foram obtidos os seguintes percentuais: 14 anos $(53,7 \%), 15$ anos $(58,9 \%)$ e 16 anos $(65,7 \%)$, mostrando que os mais velhos têm mais competência nessa dimensão que os mais novos.

Quando comparados os tipos de escola, o nível avançado teve maior percentual na categoria privada $(68,7 \%)$, seguida da pública $(58,1 \%)$ e privada com incentivo público $(31,3 \%)$, indicando que a escola privada ou a condição socioeconômica do aluno pode interferir na ampliação do nível de competência nessa dimensão.

Já em relação à formação, destaca-se que 50\% daqueles que nunca obtiveram formação estão no nível avançado e os outros 50\% encontram-se no nível básico/ intermediário. Ou seja, os alunos obtiveram um nível avançado, aprendendo sozinhos (62\%), com familiares (67\%) ou com amigos/colegas (54,3\%) mesmo sem formação específica. Daqueles que obtiveram alguma formação e estão no nível avançado, 57,1\% aprenderam em workshops e 51,4\% com professores.

\subsection{Estética}

A dimensão estética ressalta a sensibilidade para reconhecer uma produção midiática que não se adéqua às exigências mínimas de qualidade estética (Ferrés \& Piscitelli, 2015, p. 14). A primeira questão desta dimensão pergunta aos alunos Qual é o anuncio de bebida que apresenta mais elementos do ponto de vista estético? 68,94\% afirmaram que a publicidade da marca Minute Maid explora mais elementos estéticos. A porcentagem reforça que os alunos reconhecem de maneira correta os elementos presentes nas imagens mostradas no questionário.

Quando questionados sobre os motivos da escolha da propaganda da Minute Maid, 23,65\% disseram que as imagens e gráficos se integravam, deixando o desenho mais atrativo, 21,44\% afirmaram que gostaram do efeito visual, 20,44\% ressaltaram que o cenário apresentava elementos da natureza. 
MONOGRAFIA

\section{Escolha do anúncio}

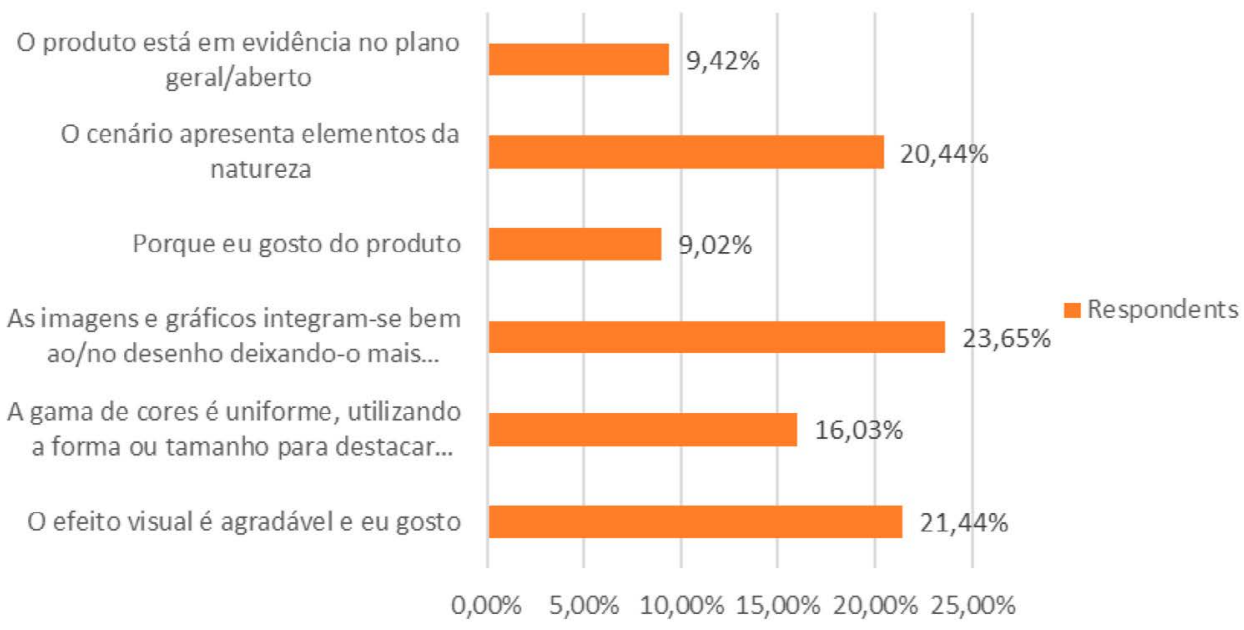

Figura 16: Respostas dos alunos

Fonte: Elaborado pelas autoras (2019).

Desta forma, a maioria foi capaz de reconhecer as características estéticas presentes na publicidade.

A última pergunta do questionário aborda o videoclipe ${ }^{11}$ da música $L a$ La $L a$, da cantora Shakira.

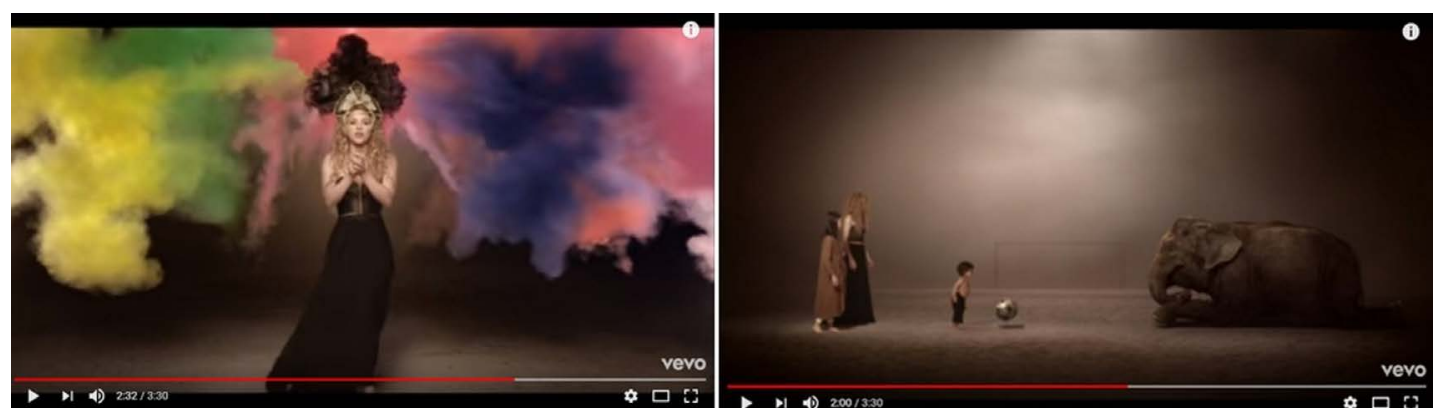

Figura 17: Trecho do videoclipe da Shakira exibido para os alunos.

Fonte: Elaborado pelas autoras (2019).

Após a exibição do conteúdo os alunos apontaram quais os elementos fazem com que o videoclipe possa ser considerado artístico. 
Razões para o videoclipe ser considerado artístico

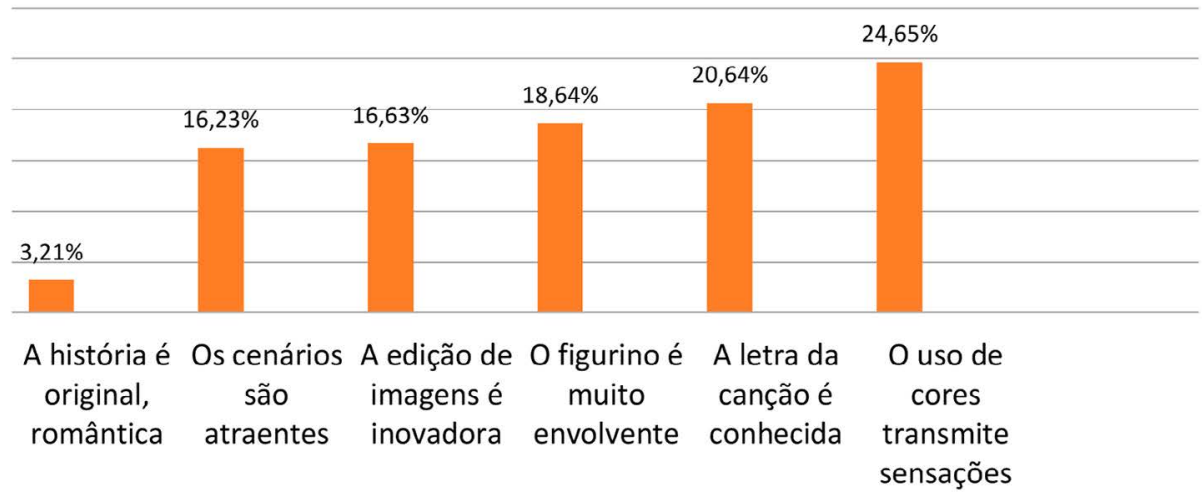

Figura 18: Respostas dos alunos

Fonte: Elaborado pelas autoras (2019).

Sendo assim, podemos concluir, com base nas respostas, que a maioria dos estudantes identificou os elementos associados à estética do vídeo exibido.

Nesta dimensão, 66,9\% dos respondentes tem nível avançado, 31,1\% tem nível básico/intermediário e $2 \%$ tem nível básico, tendo sido a dimensão que apresentou o maior percentual no nível avançado, mostrando que apesar de ser uma dimensão complexa os respondentes demonstraram ter uma relativa intimidade com ela.

\section{Estética}

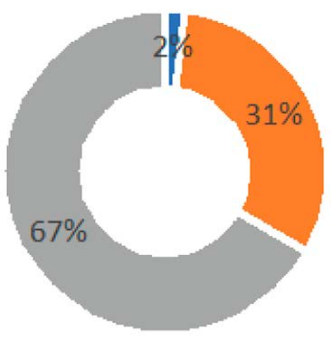

Figura 19: Níveis de competência midiática da dimensão estética

Fonte: Elaborado pelas autoras (2019). 
Em relação ao nível avançado, a variável sexo feminino apresentou um maior percentual $(66,9 \%)$ do que o masculino $(63,8 \%)$. Em relação à idade obteve-se o seguinte registro: 14 anos (65,8\%), 15 anos $(63,7 \%)$ e 16 anos (71,1\%). Considerando o tipo de escola, os resultados obtidos foram: na escola privada $(72,5 \%)$, escola pública $(67,3 \%)$ e escola privada com incentivo público $(40,6 \%)$, indicando que as escolas privadas têm prevalência significativa, pincipalmente em relação às privadas com fundo público.

Já em relação à formação, os dados obtidos para o nível avançado foram os seguintes: workshops $(71,4 \%)$, autodidata $(70,4 \%)$, nunca tive formação $(67,9 \%)$, familiares $(67,4 \%)$, aprendi na escola $(25,6 \%)$, amigos/colegas $(60,8 \%)$ e professores $(59,5 \%)$.

\section{Discussão}

Conforme o gráfico abaixo, ressaltamos a predominância do nível avançado entre as dimensões Tecnologia, Linguagem, Ideologia e Valores e Estética, tendo o nível básico-intermediário se destacado apenas em relação aos Processos de Interação e de Produção e Difusão. Porém, mesmo nas dimensões que encontramos os níveis avançados, a diferença em relação ao nível básico/intermediário não é muito grande, uma vez que os índices estão entre os $40 \%$ e os $60 \%$. Nas dimensões processos de interação e processos de produção e difusão, em que se destaca o nível básico/intermediário, é que encontramos maior distância em relação ao nível avançado.

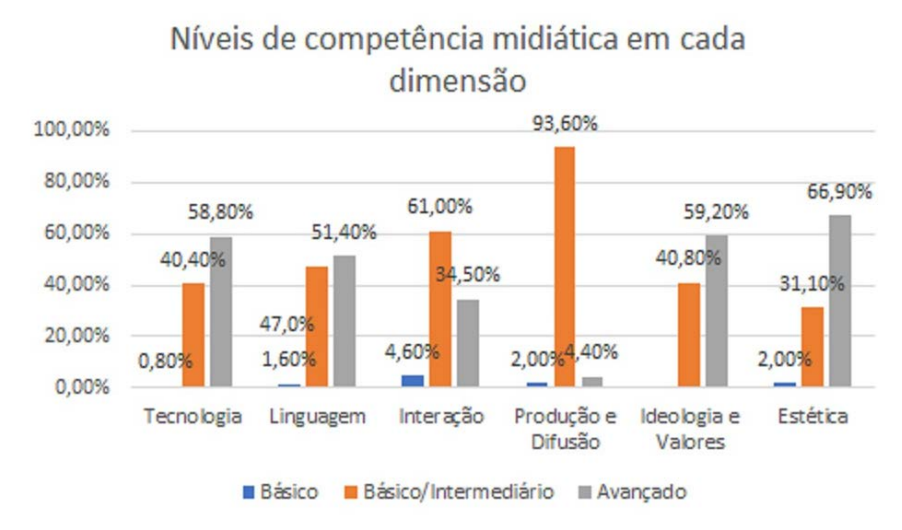

Figura 20: Niveis de competência midiática em cada dimensão Fonte: Elaborado pelas autoras (2019). 
MONOGRAFIA

Neste sentido, podemos destacar que os jovens têm competência midiática satisfatória para lidar com a tecnologia, sabendo acessar e manipular dados em sites e redes sociais, câmeras e programas de edição; bem como entender as mensagens midiáticas e produzir sentido a partir dos diferentes elementos textuais, visuais, audiovisuais e sonoros relacionados à dimensão linguagem.

Em relação à dimensão ideologia e valores, é interessante pontuar que há vinte pontos de diferença entre os dois níveis, e isso expressa a competência para entender as representações midiáticas e o modo como moldam nossa percepção da realidade, bem como a capacidade de gerir as emoções em relação às diferentes mensagens midiáticas em função dos valores que transmitem. No que se refere à estética, que está relacionada com a capacidade de reconhecer os aspectos formais que compõem uma mensagem midiática e de identificar as categorias estéticas básicas como a inovação formal e temática e a originalidade, destacamos que alcança o nível mais avançado de todas as dimensões.

Torna-se importante refletir sobre a preponderância do nível básico/intermediário nas dimensões processos de interação (34\%) e processos de produção e difusão $(4,4 \%)$, que estão relacionadas com o consumo midiático, com o modo como 0 indivíduo se comporta na internet e nas redes sociais, sendo capaz de avaliar os efeitos cognitivos das emoções; criar e alimentar redes de colaboração, bem como elaborar, selecionar, se apropriar e transformar mensagens midiáticas.

No senso comum, entende-se que os jovens sabem se movimentar muito bem pela cultura digital, sendo capazes não apenas de produzir conteúdos como também disseminá-los. 0 que esta pesquisa nos mostra é que este entendimento não se aplica ao grupo de alunos pesquisados em diferentes cidades brasileiras.

A seguir, analisamos os dados referentes à formação daqueles que têm um nível avançado de competência midiática. Nesta reflexão, priorizamos uma visão geral das práticas, saberes e competências dos jovens estudantes que participaram da pesquisa, sem especificar os recortes etários, as localizações geográficas, buscando articular as diversas dimensões da competência nos desafios das práticas formativas. 
A partir dos gráficos abaixo, num exercício de aproximação para dar visibilidade aos processos de aprendizagem, "como e com quem aprendeu/adquiriu tal conhecimento", é possível observar nuances de tais presenças/ausências a partir dos diferentes níveis.

\section{Nível avançado de fonte de aquisição de conhecimento em todas as dimensões}

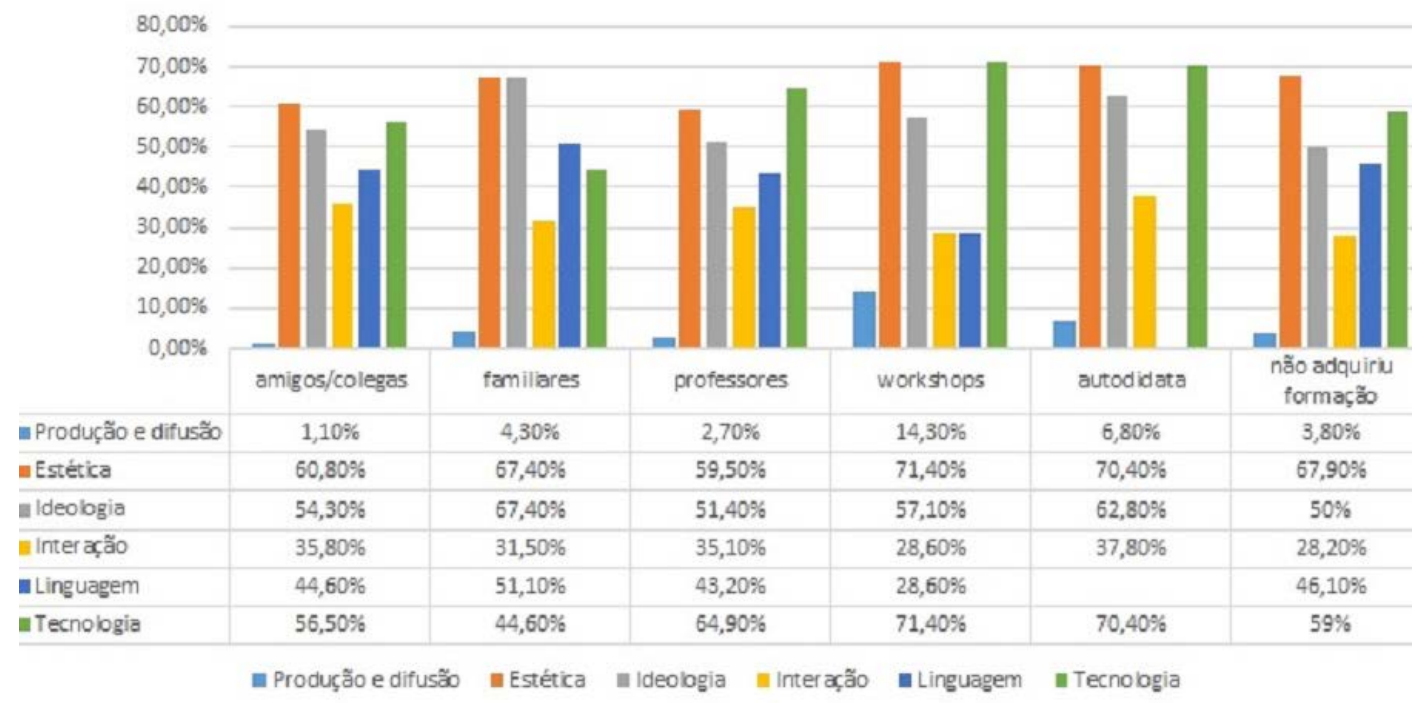

Figura 21: Nivel avançado de fonte de aquisição de conhecimento em todas as dimensões Fonte: Elaborado pelas autoras (2019).

Como podemos notar, o gráfico mostra que o aprendizado informal e não-formal, realizado por meio de amigos/colegas e familiares, respectivamente, é mais significativo nas dimensões estética $(60,8 \%$ e $67,4 \%)$ e ideologia e valores $(54,3 \%$ e $67,4 \%$ ). Ainda, na dimensão tecnologia, 56,5\% afirmam que aprenderam com os amigos, referendando a ideia da aprendizagem no espaço informal e não-formal, do capital cultural e das práticas colaborativas. De certa forma, tais dados dialogam com o que Pretto (2014, p. 346) tem destacado a respeito das práticas midiáticas e das formas de participação dos jovens que tomaram as praças e ruas do país em diversos movimentos entre os anos de 2013-2016, evidenciando a importância das redes sociais ao pautar as empresas de mídia a partir de uma diversidade de rei- 
MONOGRAFIA

vindicações. Pretto (2014) tem denominado de geração alt-tab aquela que, além de usar as teclas com destreza, "navega pelas ruas das cidades com a mesma intimidade com que navega pelas diversas telas abertas de seu desktop" (pp. 347). Para o autor, tais práticas demandam uma mudança radical na perspectiva da escola no sentido de estabelecer as necessárias interlocuções entre o que acontece dentro e fora da sala de aula, as aprendizagens formais e informais e as possibilidades de mediação.

Em relação ao aprendizado formal, realizado com professores e por meio de workshops, destaca-se, respectivamente, as dimensões tecnologia (64,9\% e 71,4\%) e estética (59,5\% e $71,4 \%)$. A esse respeito, vale lembrar as vertentes da mediação educativa que Livingstone (2017) destaca: capacitadora (conversa, encorajamento, aconselhamento) e restritiva (insistência, proibição, restrição) a partir de estudos anteriores que evidenciavam as dimensões de uso compartilhado, limite e restrição de tempo e conteúdo, restrição técnica e monitoramento (Livingstone \& Helsper, 2008, p. 585).

Aqueles que afirmam que aprenderam sozinhos e que não tiveram formação se destacam nas dimensões estética $(70,4 \%$ e $67,9 \%)$ e tecnologia $(70,4 \%$ e $59 \%$ ), respectivamente. Talvez esses dados possam sugerir tanto o sentido de uma autodidaxia (Belloni \& Gomes, 2008, p. 721) como aspectos do movimento Do It Yorself ou movimento da cultura maker, caracterizado pelos slogans "faça você mesmo", "coloque a mão na massa" e/ou "experimente e produza" a partir dos novos modos de participação na cultura digital, evidenciando possibilidades de "[...] um novo tipo de solução educativa com uma aprendizagem automotivada e organizada, possibilitada pela tecnologia digital" (Sefton-Green, 2013, p. 13).

Por outro lado, podemos analisar a partir do gráfico a seguir as fontes de aquisição de conhecimento nas diferentes dimensões que se encontram no nível básico/intermediário. 


\section{Nível básico/intermediário de fonte de aquisição de conhecimento em todas as dimensões}

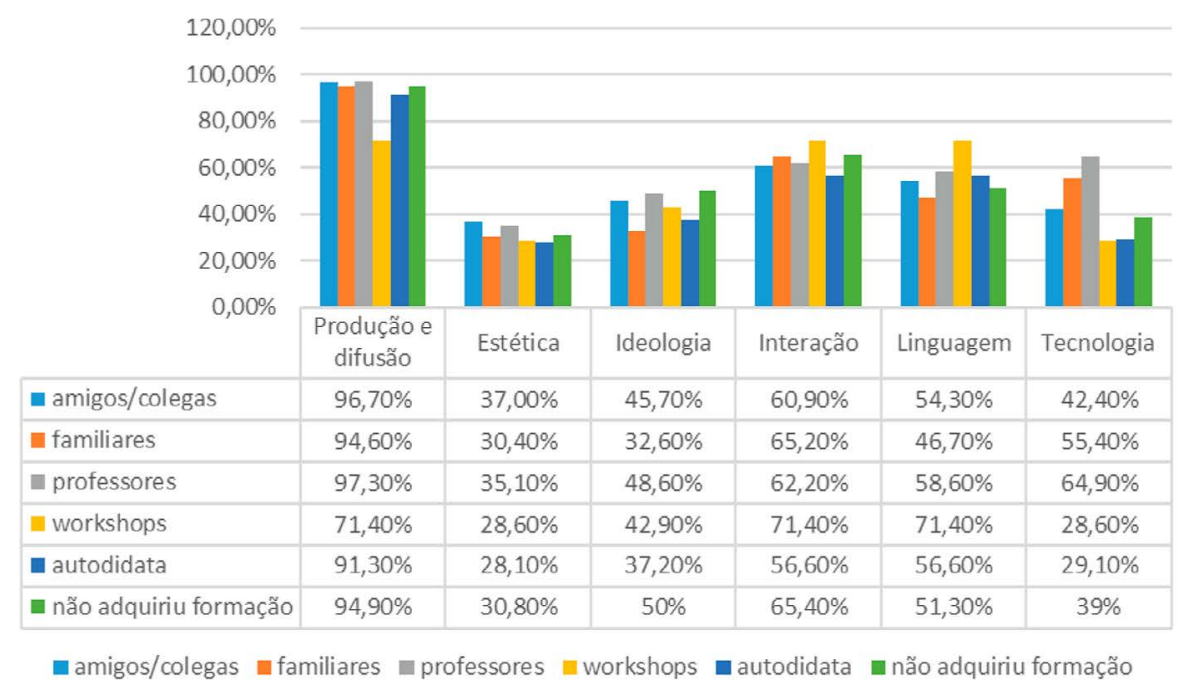

Figura 22: Nivel básico/intermediário de aquisição de conhecimento em todas as dimensões Fonte: Elaborado pelas autoras (2019).

Sendo assim, podemos identificar que as outras dimensões da competência midiática, nomeadamente linguagem, processos de interação e processos de produção e difusão precisam receber atenção especial a fim de que sejam desenvolvidas neste grupo pesquisado. Porém, na dimensão produção e difusão, que apresentou baixo nível de competência, destacam-se os professores $(97,3 \%)$, que parecem ter assumido um papel determinante em tal aprendizagem.

A dimensão linguagem encontra-se no nível básico/intermediário para todos os quesitos estudados, com exceção dos familiares (51,10\%), que se encontram no nível avançado com uma diferença de cinco pontos percentuais em relação ao nível básico/intermediário. A dimensão processos de interação e processos de produção e difusão encontram-se no nível básico/intermediário para todos os quesitos com diferença entre vinte e cinquenta e cinco pontos percentuais, respectivamente, em relação ao nível avançado.

Se sinalizamos acima a possível presença da autodidaxia e de aspectos do movimento Do It Yourself em seu caráter afirmativo, aqui tais espaços de formação tam- 
MONOGRAFIA

bém permitem desmistificar um pouco a importância do "aprender sozinho" e até mesmo da ideia de "nativo digital" (Fantin, 2016, p. 6). Afinal, para a autora, "tão importante quanto usar os meios que dão sentido às práticas educativas, culturais e midiáticas, que modificam a dinâmica das negociações dos jovens sobre suas aprendizagens é conhecer as estratégias que usam para aprender e atuar dentro e fora da escola". Só assim será possível promover mediações significativas para que eles possam "aprender a interconectar informações, conhecimentos, linguagens e afetos, na base das vivências e experiências" (Carvalho et al., 2013, p. 373). Neste sentido, "dialogar com as culturas juvenis na escola implica estar atento às experiências dos jovens estudantes e seus processos de produção de subjetividades" (Fantin, 2019, p. 381), pois isso é fundamental para articular os saberes e as vivências cotidianas de forma significativa na construção das dimensões da competência midiática na escola.

Sendo assim, a partir da pesquisa realizada nas seis cidades brasileiras, que tem o intuito de compreender o universo no qual as universidades envolvidas desenvolvem atividades de formação em mídia-educação, podemos concluir que os jovens se movimentam com desenvoltura no manuseio da tecnologia, e também percebem os elementos estéticos e os significados associados às mensagens midiáticas, sabendo interpretar e analisar conteúdos de forma satisfatória.

Porém, percebemos que as dimensões processos de interação e de produção e difusão, que estão relacionados com o consumo e a participação midiática, precisam de ações de formação no sentido de promover a aprendizagem e o desenvolvimento do espírito crítico. Assim, podemos contribuir para fortalecer o papel da educação na construção de experiências de cidadania que possibilitem uma formação responsável e sintonizada com os desafios da complexidade.

\section{Referencias}

Aguaded, I.. (2012). Media proficiency, an educational initiative that cannot wait. [La competencia mediática, una acción educativa inaplazable]. Comunicar, 39, 07-08. https://doi.org/10.3916/C39-2012-01-01

Belloni, M. L.; Gomes, N. G. (2008). Infância, mídias e aprendizagem: autodidaxia e colaboração. Educação \& Sociedade, 29 (104), 717-746. http://bit.ly/2nIljLU. 
Borges, G., Silva, M. B. (2019). Competências midiáticas em cenários brasileiros e euroamericanos (Report No. 2070.01.0001118/2020-85). Fapemig - Fundação de Amparo à Pesquisa do Estado de Minas Gerais.

Buckingham, D. (2005). Media Education: literacy, learning and contemporary culture. Polity Press.

Carvalho, J. M., Silva, S. K., Delboni, T. M., Pais, J. M. (2013). Entre culturas, pesquisas, currículos e cotidianos: uma conversa com J. M. Pais. Currículo Sem Fronteiras, 13(3), 361-374. http://www.curriculosemfronteiras.org/ vol13iss3articles/carvalho-silva-delboni-pais.htm

Creswell, J. W. (2010). Projeto de pesquisa: métodos qualitativo, quantitativo e misto. (3rd ed.). Artmed.

European Commission. (2018). DigComp. The European Digital Competence Framework. Publications Office for the European Union. https://op.europa. eu/en/publication-detail/-/publication/3d35b6b6-d8f8-11e9-9c4e01aa75ed71a1/language-en

European Commission. (2019). Key competences for lifelong learning. Publications Office for the European Union. https://op.europa.eu/en/publication-detail/-/ publication/297a33c8-a1f3-11e9-9d01-01aa75ed71a1/language-en

Fantin, M. (2016). Nativos e imigrantes digitais em questão: crianças e competências midiáticas na escola. Passagens, 7(1), 5-26. http://www.periodicos.ufc.br/ passagens/article/download/3652/3279

Fantin, M. (2019). Jovens, cultura e educação: dispositivos da arte e da tecnologia na escola. In. V.L. Colaço; I. Germano; L.L. Miranda; J.P. Barros (Ed.) Juventudes em movimentos: experiências, redes e afetos (1sr ed., pp. 437-390). Expressão.

Ferrés, J.. (2007). Competence in media studies: its dimensions and indicators. [La competencia en comunicación audiovisual: dimensiones e indicadores]. Comunicar, 29, 100-107. https://doi.org/10.3916/C29-2007-14

Ferrés, J. \& Piscitelli, A. (2015). A competência midiática: proposta articulada de dimensões e indicadores. Lumina, 9(1), 1-16. https://doi.org/10.34019/19814070.2015.v9.21183

García-Ruiz, R., Gozálvez Pérez, V., \& Aguaded Gómez, J. (2014). La competencia mediática como reto para la educomunicación: instrumentos de evaluación. Cuadernos.Info, (35), 15-27. https://doi.org/10.7764/cdi.35.623. 
MONOGRAFIA

Gil, A. C. (2008). Como elaborar projetos de pesquisa (4th ed.). Atlas. Hernández-Sampieri, R., Fernández-Collado, C., Baptista-Lucio, M. P. (2013). Metodologia de la Investigación (6th ed.). Mc-GrawHill.

Hobbs, R. (2006). Multiple visions of multimedia literacy: Emerging areas of synthesis. In M. C. McKenna, L. D. Labbo, R. D. Kieffer, \& D. Reinking (Eds.), International handbook of literacy and technology, volume II (pp. 15-28). Lawrence Erlbaum Associates. Livingstone, S. (2017, February, 17) Digital skills matter in the quest for the 'holy grail'. Parenting for a Digital Future. http://bit.ly/2nIwXX8

Livingstone, S.; Helsper, E. (2008). Parental mediation and children's Internet use. Journal of broadcasting \& electronic media, 52(4), 581-599. https://doi. org/10.1080/08838150802437396

Pretto, N. (2014). Redes sociais e educação: o que quer a geração alt+tab nas ruas? Liinc em Revista, 10(1), 344-350. https://doi.org/10.18617/liinc.v10i1.643

Rivoltella, P.C.. (2005). Educating media competence: new ways of consumption and educational perspectives. [Formar a competência midiática: novas formas de consumo e perspectivas educativas]. Comunicar, 25. https://doi.org/10.3916/C25-2005-167

Rivoltella, P.C.. (2008). From Media Education to Digital Literacy: A Paradigma Change? In P.C. Rivotella (Ed.), Digital Literacy. Tools and Methodologies for Information Society (1st ed., pp. 217-229). Idea Group Publishing.

Rivoltella, P.C.. (2010). Consumi mediali e competenze di cittadinanza. REM Ricerche su Educazione e Media, 2(1), 5-8.

Schneider, E. M.; Fujii, R. A. X.; Corazza, M. J.. (2017). Pesquisas quali-quantitativas: contribuições para a pesquisa em ensino de ciências. Revista Pesquisa Qualitativa, 5(9), 569-584. https://editora.sepq.org.br/index.php/rpq/article/view/157

Sefton-Green, J. (2013). Mapping digital makers a review exploring everyday creativity, learning lives and the digital. Nominet Trust. http://www. julianseftongreen.net/wp-content/uploads/2013/03/NT-SoA-6-FINAL.pdf

Sefton-Green, J. (2019). Por uma história cultural do autodidatismo digital: mudanças nas narrativas culturais da educação. Perspectiva, 37(1), 125-139. https://doi.org/10.5007/2175-795X.2019.e52964

União Europeia. (2006). Recomendação do Parlamento Europeu e do Conselho de 18 de dezembro de 2006 sobre as Competências Essenciais para a aprendizagem ao longo da vida. Jornal Oficial da União Europeia. L294/10 (30/12/2006). https://eurlex.europa.eu/legal-content/PT/TXT/PDF/?uri=CELEX:32006H0962\&from=EN 
União Europeia. (2018). Recomendação do Conselho de 22 de maio de 2018 sobre as Competências Essenciais para a aprendizagem ao longo da vida. Jornal Oficial da União Europeia. C189/01 (04/06/2018). https://eur-lex.europa.eu/legalcontent/PT/TXT/PDF/?uri=CELEX:32018H0604(01)\&from=EN

\section{Notas}

[1] Para o seu desenvolvimento esta pesquisa contou com financiamento do CNPQ - Conselho Nacional de Desenvolvimento Científico e Tecnológico, Edital MCTI/CNPq/MEC/CAPES Chamada $n^{0}$ 14/2014 - Ciências Humanas Sociais e Sociais Aplicadas (processo no 449573/2014-1) e da Fapemig - Fundação de Amparo à Pesquisa do Estado de Minas Gerais do Edital 01/2015 - Demanda Universal 2015 (processo APQ CHE 002824-15) e da Universidade Federal de Juiz de Fora e do Programa Universidade sem Fronteiras da Secretaria de Ciência e Tecnologia do Estado do Paraná.

[2] A Rede Interinstitucional Euroamericana de Investigação sobre Competência Midiática para a Cidadania (Alfamed) é composta por 13 países da América Latina e Europa, coordenada pelo professor catedrático José Ignacio Aguaded Gomez, da Universidade de Huelva.

[3] No formato CSV (Comma-Separated Values).

[4] Em Brasília foram aplicados 131 questionários, em Florianópolis 103, em Juiz de Fora 121, em Ponta Grossa 100, em São Roque 10 e em Sorocaba 34. Totalizando 499 questionários.

[5] Os dados foram tratados com o auxílio dos estatísticos: Daniel Moreira (Tratamento inicial) e José Ricardo Favoretto (Tratamento pormenorizado).

[6] 0 quiquadrado compara valores observados e esperados indicando se há uma relação significativa.

[7] Escolas onde foram aplicados os questionários: CED do Lago, CEF 306 Norte, CEM Setor Leste, CEM Setor Oeste, Centro de Ensino Médio Asa Norte, Centro Educacional Marista Lúcia Mayvorne, Colégio Aplicação, Colégio Equipe, Colégio Estadual Manuel Antônio Gomes, Colégio Estância de São Roque, Colégio SESI, Escola Municipal Doutor Achilles de Almeida, Escola Municipal Doutor Antonino Lessa, Escola Municipal Santos Dumont, Sistema Degraus de Ensino.

[8] Formato de compressão de áudio digital e dispositivo que reproduz o mesmo.

[9] Formato de compressão de áudio e vídeo digital e dispositivo que reproduz o mesmo.

[10] Disponível em https://vimeo.com/189118397

[11] Disponível em https://www.youtube.com/watch?v=7-7knsP2n5w.

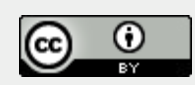

Este obra está bajo una licencia de Creative Commons Reconocimiento 4.0 Internacional. 